\title{
Perhitungan Daya Output PLTMH di Jalan Bintara Sungai Duren Jambi
}

\author{
Kriswanto $^{1^{*}}$, S. Umar Djufri ${ }^{2}$ \\ ${ }^{1,2}$ Teknik Listrik, Fakultas Teknik, Universitas Batanghari \\ *Correspondence Email: cuweng1995@gmail.com; umar.djuhfri@unbari.ac.id
}

\begin{abstract}
Abstrak. Di Indonesia tidak semua mendapatkan aliran listrik sepenuh nya, di daerah-daerah terpencil cukup banyak yang tidak mendapat sumber energi listrik, akan tetapi di Indonesia cukup banyak aliran air anak serperti aliran sungai aliran irigasi hal di karna kan banyak nya dataran tinggi hal inilah dapat di manfaat kan sebagai sumber energi listrik, PLTMH sangat la bagus di gunakan di daerah-daerah perbukitan dengan biaya pembuatan yang tidak tergolong mahal dan tidak begitu susah dalam pengerjaan nya. PLTMH ini menggunakan pipa ukuran 2inch dan jatuh air terjun yang di gunakan yang ideal 0,2 $\mathrm{m}$ dan diameter turbin 0,4 jari-jari 0,2 speksifikasi generator 18 Volt 15 Ampere menggunakan aki 32ampere/jam untuk penyimpanan daya yang di hasilkan oleh PLTMH dan inverter sebegai merubah arus dc ke ac daya yang di hasilkan PLMH. Dengan putaran turbin yang di dapat PLTMH 80 Rpm dan menghasilkan daya output turbin 10,705 Watt dengan daya kluaran generator dan daya output PLTMH 7,996 Watt.
\end{abstract}

Kata Kunci: Perhitungan daya output PLTMH di jalan bintara sungai duren jambi

Abstract. In Indonesia, not all of them get full electricity, in many regions there are not enough sources of electrical energy, but in Indonesia there are quite a lot of child air currents such as halal rivers because the benefits are as a source of electrical energy, PLTMH is very good to be used in hilly areas with manufacturing costs that are not quite expensive and not so difficult in its workmanship. This PLTMH uses a 2inch pipe size and a waterfall fall that is ideally used $0.2 \mathrm{~m}$ and turbine diameter 0.4 radius 0.2 specifier 18 Volt 15 Ampere generator uses 32 ampere / hour battery for storage of power generated by PLTMH and the inverter converts the dc current to ac power generated by PLMH. With the turbine rotation that is obtained by PLTMH 80 Rpm and produces 10.705 Watt turbine output power with generator output power and 7.996 Watt PLTMH output power

Keywords: calculation of power output PLTMH in the river NCO, Duren Jambi

\section{PENDAHULUAN}

Energi listrik merupakan energi yang \Kegiatan manusia dengan listrik menjadi lebih lancar, penyebaran informasi menjadi lebih cepat dan mudah, serta dapat meningkatkan kesejahteraan manusia..

Daerah pedesaan terpencil yang sebagian besar daerah nya belum terjangkau jaringan Perusahaan Listrik Nasional (PLN) merupakan suatu masalah bagi pembangunan dan pengembangan masyarakat pedesaan. Kebutuhan akan energi listrik merupakan kebutuhan yang tidak dapat ditawartawar lagi untuk kehidupan yang layak bagi setiap orang pada zaman sekarang ini.

Umumnya daerah pedesaan terpencil yang terletak pada daerah pegunungan mempunyai potensi energi air yang besar, sehingga pembangkit listrik tenaga air skala mikro merupakan salah satu sumber energi yang dapat dikembangkan.

Sebuah pembangkit listrik sederhana yang dapat dikembangkan untuk pembangkitan listrik rumah tangga di pedesaan terpencil sehingga rumah tangga yang berada di pedesaan dapat menghasilkan energi listrik untuk diri mereka sendiri dan bekerja secara kontinu

Daya output dari generator yang di hasilkan di manfaatkan untuk kebutuhan rumah tangga Daya tersebut di distribusikan, sesuai kapasitas yang di hasilkan oleh pembangkit.

\section{Daya yang di bangkitkan}

Besarnya daya yang dihasilkan merupakan fungsi dari besarnya debit sungai dan tinggi terjun air. Besarnya debit yang dipakai sebagai debit rencana, bisa merupakan debit minimum dari sungai tersebut sepanjang tahunnya atau diambil antara debit minimum dan maksimum, tergantung fungsi yang direncanakan PLTMH tersebut. Besarnya tinggi terjun air terikat pada kondisi geografis di mana PLTMH tersebut berada. Panjangnya lintasan yang harus dilalui air dari bendungan ke turbin menyebabkan hilangnya sebagian energi air, energi air yang tersisa (tinggi terjun efektif) inilah yang menggerakkan turbin air dan kemudian turbin air ini yang menggerakkan generator. Besarnya daya yang dihasilkan juga tergantung dari efisiensi keseluruhan (overall efficiency) PLTMH tersebut yang terdiri dari efisiensi hidrolik, yaitu perbandingan antara energi efektif dan energi kotor (bruto), efisiensi turbin dan efisiensi generator. Dengan demikian besarnya daya dapat dirumuskan sebagai berikut:

$\mathrm{P}=\rho \times \mathrm{Q} \times \mathrm{g} \times \mathrm{H} \times \eta$

dimana:

$\rho \quad=$ densitas air $(\mathrm{kg} / \mathrm{m} 3)$

$\mathrm{Q}=$ debit air ( $\mathrm{m} 3 /$ detik)

$\mathrm{h} \quad=$ tinggi terjun air efektif (m)

$\eta \quad=$ efisiensi keseluruhan 
$\eta=\eta_{\mathrm{T}} \mathrm{x} \eta_{\mathrm{g}}$

dimana:

$\eta_{\mathrm{t}} \quad=$ efisiensi turbin

$\eta_{\mathrm{g}} \quad=$ efisiensi generator

Efisiensi turbin di peroleh dengan persamaan:

$\eta_{\mathrm{T}}=\frac{\mathrm{PT}}{\mathrm{PH}} \times 100 \%$

Debit air adalah jumlah volume air yang mengalir persatuan waktu, dapat diproleh dengan persamaan:

$\mathrm{Q}=\frac{v}{t}$

dimana:

Q $\quad=$ Debit

$\mathrm{V} \quad=$ Kecepatan air

A $\quad=$ Luas penampang pipa

Untuk mencari Q Kita harus mencari V terlebih dahulu apabila terjadi perubahan jatuh air pada suatu aliran, maka kecepatan air yang di hasilkan akan smkin tinggi juga, kecepetan air dapat di tentukan dengan persamaan:

$\mathrm{V}=\sqrt{2 g h}$

Mencari luas penampang pipa di rumuskan dengan persamaan berikut:

$\mathrm{A}=1 / 4 \times \mathrm{x} \mathrm{D}^{2}$

Daya air $\mathrm{P}_{\mathrm{H}}$ diproleh dengan persamaan

$\mathrm{P}_{H}=\rho x g x Q \times h$

Adalah daya yang di bangkitkan dari aliran arus air yang menentukan kincir dapat berputar

$\mathrm{F}=\mathrm{A} \times \rho \times \mathrm{v}^{2}$

Torsi yang di hasilkan kincir, di tentukan dengan persamaan

$\mathrm{T}=\mathrm{F} \times \mathrm{r}$

Daya kincir $\left(\mathrm{P}_{\mathrm{T}}\right)$ diperoleh dengan persamaan

$\mathrm{P}_{\mathrm{T}}=\mathrm{T} \times \omega$

Efisienis Turbin diproleh dengan persamaan

$\eta_{t}=\frac{\mathrm{PT}}{P H}$

\section{Operasional Mikrohidro}

Jika semua komponen mikrok hidro dibuat dan dipasang lapangan, maka pekerjaan selanjutnya yang paling penting adalah mengoprasikan mikro hidro secara teknis, oprasional mikro hidro adalah mengalirkan air menuju turbin agar rotor dapat berputar maksimal dan menghasilkan putaran yang mampu memutar generator sinkron pada putaran (rpm) yang dihendaki. Pada umum nya listrik mikro hidro hanya menyala di sore hari sampai dengan pagi hari. Umum nya listrik di nyalakan pada 6 sore dan mati pada 6 pagi. Namun pada kondisi pondok turbin yang jauh dari pemukiman sering kali operator menjalakan mesin pada jam 4-5 sore dan mematikan mesin anatara jam 7 sampai 8 pagi.

Langkah-langkah penting dalam menjalankan PLTMH (menyalakan listrik) adalah sebagai berikut:

1. Pastikan inlet guide vone dalam posisi tertutup

2. Pastikan MCB aliran masuk dan MCB aliran keluar pada panel distribusi dalam posisi off (mati)

3. Pastikan tidak ada sampah di saringan,bak, dan juga saluran terbuka

4. Alirkan air dari inlet menuju saluran terbuka dengan membuka pintu air di inlet yang mengarahkan ke saluran dan menutup pintu buangan

5. Aliran air sampai dengan bak penenang penuh dan air tertutup melaluin spillway yang di buat di bak

6. Naikan switch MCB aliran masuk ke posisi on

7. Perlahan buka inlet guinde vane dengan memutar kemudian stang pengatur air samapai puli mesin berputar, demikian juga dengan puli generator. Karena pada putaran puli terjadi percepatan maka bukaan harus di lakukan bertahap.

8. Setelah putaran puli mesin stabil, perlahan naikan putaran sambil mengamati pergerakan jarum pada voltmeter yang naik menujju tegangan yang di hendaki (22O volt)

9. Naikan switch MCB aliran kluar ke posisi on. pada kondisi ada beban seperti ini,akan tegangan akan menurun. Jarum pada voltmeter akan turun pada posisi semula.

10. Tambahkan bukaan inlet guinde vane dengann memutar kembali kemudi stang pengatur sambil terus mengawasi jarum pada voltmeter

11.Hentikan bukaan setelah jarum pada voltmeter menunjukan angka 180-220volt sesuai tegangan yang di hendak

Selanjutnya adalah langkah-langkah dalam mematikan PLTMH adalah sebagai berikut:

1. Buka pintu air buangan di inlet dan tutup pintu aliran air masuk ke saluran terbuka

2. Perlahan tutup inlet guinde vane dengan memutar kemudi pengatur berlawanan arah dengan bukaan. Penutupan harus di lakukan secara perlahan untuk menghindari tekanan yang tiba-tiba pada pipa pesat yang berisiko pecahnya pipa pesat pada kondisi ini tegangan akan turun secara perlahan

3. Setelah jarum tegangan menunjukan angka 0.turunkan switch MCB aliran kluaran pada posisi off

4. Biarkan bukaan inlet guinde vane tetap sedikit terbuka agar air di 
5. dalam pipa pesat bisa dikosongkan, namun air yang mengalir tidak menggerakan turbin

Kunci utama dari oprasional PLTMH adalah tersedianya aliran air dalam jumlah yang kontinu. Dengan demikian, maka tugas operator selain menyalakan dan mematikan mesin adalah mengawasi agar tidak ada gangguan sampah yang bisa mengganggu kontinuitas aliran air menuju turbin.

\section{METODE}

Pengambilan data dan analisa data untuk penelitian ini di lakukan di lokasi PLTMH yaitu di JL.Bintara Simp.Sei Duren jambi, pada tanggal 20 Desember 2019 sampai 20 Januari 2020.

\section{Diagram alur}

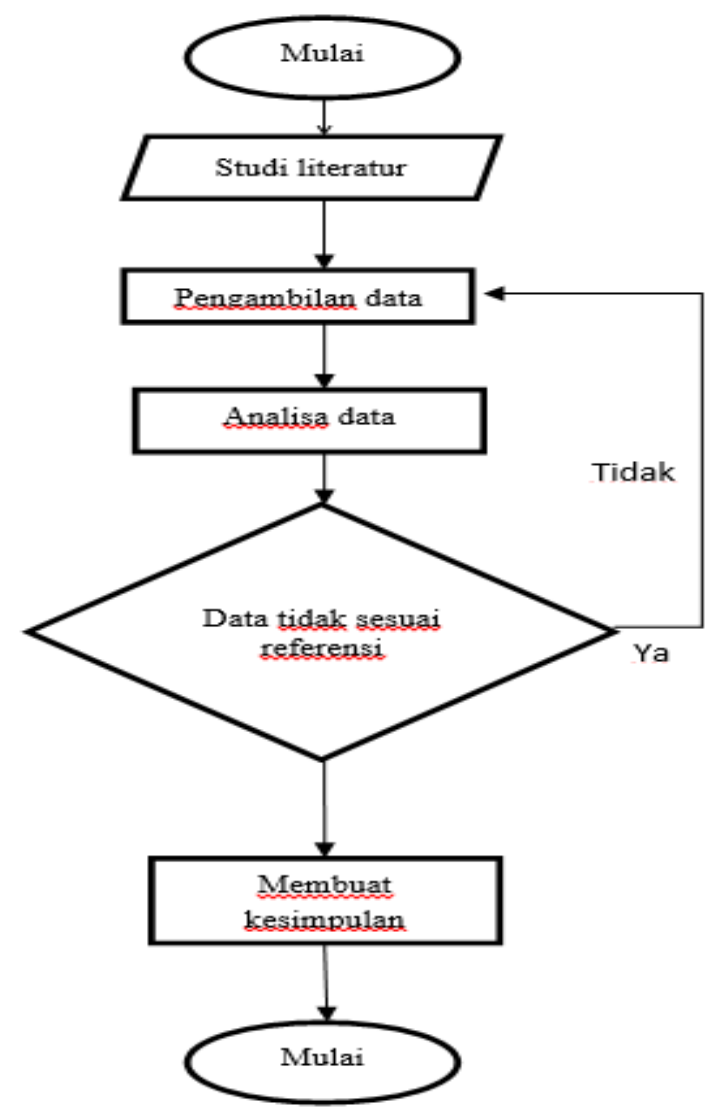

Gambar 1. Diagram alur

\section{Studi Literatur}

Mencari daya yang dihasilkan oleh pembangkit listrik tenaga mikrohidro PLTMH suasai pada data riferensi pengambilan data di lakukan pada lokasi di JL.Bintara Simp.Sei Duren jambi

\section{Pengambilan data}

Pengambilan data dilakukan pada saat pembangkit listrik tenaga mikrohidro pada saat beroprasi dengan maksimal

\section{Analisa data}

Setelah data telah di dapat maka masi ada yang nama nya analisa data yang bertujuan untuk menganalisa data tersebut apakah sesuai dengan yang di harapkan atau yang di tentukan riferensi

\section{Data tidak sesuai referensi}

Jika data yang di dapat pada PLTMH tidak sesuai referensi maka kita akan melalukan pengambilan data ulang.

\section{HASIL DAN PEMBAHASAN}

Hasil peneletian PLTMH yang di lakukan di jalan bintara sungai duren jambi .dengan menggunkan diameter pipa 2 inch panjang pipa 7 meter diameter turbin $0,4 \mathrm{~m}$ menggunakan speksifikasi generator 18 Volt 15 Ampere menggunakan aki 32ampere/jam dan inverter 12 Volt.

\section{Data Teknis PLTMH}

Data teknis yang di dapat untuk Pembngkit Listrik Tenaga Mikrohidro (PLTMH) yang di rancang di Jalan Bintara Sungai Duren Jambi sebagai berikut:
1. Panjang pipa
: 7 meter
2. Diamter pipa
: 2 inchi $(0,0508 \mathrm{~m})$
3. Tinggi jatuh air
$: 0,2 \mathrm{~m}$
4. Diameter turbin
$: 0,4 \mathrm{~m}$
5. Rpm turbin
: $80 \mathrm{Rpm}$
6. Berat turbin
$: 2 \mathrm{~kg}$
7. Generator rpm, 250 Watt
8. Masa jenis air
: DC, $12-18 \mathrm{~V}, 500-1000$
9. Gravitasi
$: 1000 \mathrm{~kg} / \mathrm{m}^{3}$
: $9,8 \mathrm{~m} / \mathrm{dt}^{2}$

\section{Perhitungan dan Analisa \\ Perhitungan daya yang di hasilkan kincir}

Langkah-langkah perhitungan daya dilakukan dengan menghitung kecepatan air (v), debit aliran air $(\mathrm{Q})$, daya air $\left(\mathrm{P}_{\mathrm{H}}\right)$, kecepatan putaran kincir $(\mathrm{n})$, gaya dorong kincir $(\mathrm{F})$, torsi $(\mathrm{T})$ dan daya kincir $\left(\mathrm{P}_{\mathrm{T}}\right)$

\section{Kecepatan Air (v)}

Untuk tinggi jatuh air (h) $0,2 \mathrm{~m}$, dan diameter pipa 3 inchi $(0,0762 \mathrm{~m})$ dengan ujung pipa 2 inchi $(0,0508 \mathrm{~m})$ menggunakan hukum Bernaully untuk fluida yaitu :

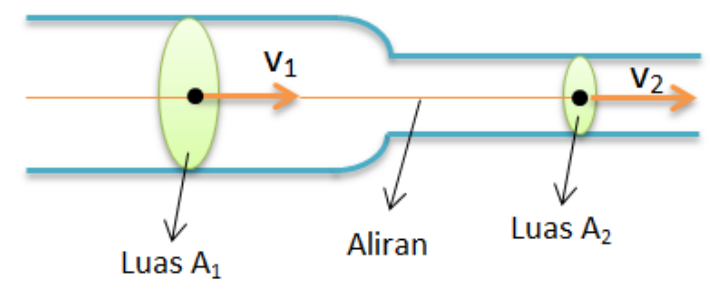

Gambar 2. Diagram Bernaully

$$
\begin{aligned}
& \mathrm{A}_{1} \times \mathrm{V}_{1}=\mathrm{A}_{2} \times \mathrm{V}_{2} \\
& \mathrm{~V}_{1}=\sqrt{\frac{2 g h}{\left(\frac{A_{1}}{A_{2}}\right)^{2}-1}} \mathrm{~m} / \mathrm{s}
\end{aligned}
$$


$\mathrm{V}_{1}=\sqrt{\frac{2 \times 9,8 \times 0.2}{\left(\frac{0,0762}{0,0508}\right)^{2}-1}} \mathrm{~m} / \mathrm{s}$

$\mathrm{V}_{1}=\sqrt{\frac{3,92}{1,25}} \mathrm{~m} / \mathrm{s}$

$\mathrm{V}_{1}=1.066 \mathrm{~m} / \mathrm{s}$

$\mathrm{V}_{2}=\frac{A_{1} \times V_{1}}{A_{2}}$

$\mathrm{V}_{2}=\frac{0,0762 \times 1,066}{0,0508}$

$\mathrm{V}_{2}=1,599 \mathrm{~m} / \mathrm{s}$

Dari perhitungan di atas diperoleh kecepatan aliran air dalam pipa adalah $1,599 \mathrm{~m} / \mathrm{s}$

\section{Debit Air (Q)}

Untuk luas penampang pipa alir air dengan diameter pipa 2 inchi (0,0508 meter) diperoleh:

$\mathrm{A}=\frac{1}{4} \times \pi \times \mathrm{D}^{2}$

$\mathrm{A}=\frac{1}{4} \times 3.14 \times 0,00581$

$\mathrm{A}=0,005 \mathrm{~m}^{2}$

Maka debit air dapat dihitung:

$Q=V \times A$

$Q=1,599 \times 0,005$

$Q=0,008 \mathrm{~m}^{3} / \mathrm{s}$

\section{Daya Hidrolis $\left(P_{H}\right)$}

Untuk densitas air $997 \mathrm{~kg} / \mathrm{m}^{3}$ dan grafitasi 9,8 $\mathrm{m} / \mathrm{s}^{2}$ diperoleh daya:

$\mathrm{P}_{H}=\rho x g \times Q \times h$ Watt

$\mathrm{P}_{\mathrm{H}}=1000 \times 9,8 \times 0,008 \times 0,2$

$\mathrm{P}_{\mathrm{H}}=15,68 \mathrm{Watt}$

\section{Gaya dorong kincir}

Adalah daya yang di bangkitkan dari aliran arus air yang menentukan kincir dapat berputar.

$\mathrm{F}=\mathrm{A} \times \rho \times \mathrm{v}^{2}$

$\mathrm{F}=0,005 \times 1000 \times 2,557$

$\mathrm{F}=12,784 \mathrm{~N}$

\section{Torsi}

Torsi yang di hasilkan kincir, di tentukan dengan persamaan:

$\mathrm{T}=\mathrm{F} \times \mathrm{r}$

$\mathrm{T}=12,784 \times 0,2$

$\mathrm{T}=2,557 \mathrm{Nm}$

Daya kincir $\left(\mathrm{P}_{\mathrm{T}}\right)$ diperoleh dengan persamaan:

$\mathrm{P}_{\mathrm{T}}=\mathrm{T} \times \omega$
$\mathrm{P}_{\mathrm{T}}=2,557 \times \frac{2 \times 3,14 \times 80}{60}$

$\mathrm{P}_{\mathrm{T}}=10,705 \mathrm{Watt}$

\section{Efisiensi Turbin}

$$
\begin{aligned}
\eta_{t} & =\frac{\mathrm{PT}}{P H} \\
\eta_{t} & =\frac{10,705}{15,68} \times 100 \% \\
\eta_{t} & =68,272 \%
\end{aligned}
$$

\section{Perhitungan Daya Output PLTMH}

Daya output PLTMH merupakan besaran beban yang mampu di suplai untuk mendapatkan daya ini turbin di kalikan dengan efisiensi generator yang ada (sesuai name plate) jadi daya listrik yang di dapat di hasilkan Pembangkit Listrik Tenaga Mikrohidro PLTMH dengan di amsumsikan efiseinsi generator $75 \%$ diproleh daya out PLTMH aldalah:

$$
\begin{aligned}
& \mathrm{P}=p \cdot \mathrm{g} \cdot \mathrm{Q} \cdot \mathrm{h} \cdot \eta_{\mathrm{t}} \cdot \eta_{\mathrm{g}} \\
& \mathrm{P}=1000 \times 9,8 \times 0,008 \times 0,2 \times 0,68 \times 0.75 \\
& \mathrm{P}=7,996 \text { watt }
\end{aligned}
$$

Watt

Maka di dapat output PLTMH adalah $=7,996$

\section{SIMPULAN}

Besar daya output dari PLTMH yang di rancang di daerah jalan bintara sungai duren jambi daya pada generator 18 Volt 15 Ampere dan daya dari PLTMH yang di buat menghasilkan daya sebesar 7,996 Watt.

\section{Saran}

Dari hasil penelitian di atas di dapat jika ingin menghasilkan daya yang besar maka diameter turbin harus di perbesar dan tinggi jatuh air lebih tinggi agar mendapatkan tekanan air yang cukup besar untuk memutar turbin pada PLTMH

\section{DAFTAR PUSTAKA}

[1] Nugroho Y.S.H Hunggul,Sallata M.Kudeng. 2015. PLTMH (Pembngkit Listrik Tenaga Mikrohidro). ,Andi Offset. Jogja karta.

[2] Syarif. 26 oktober 2015. Bendungan PLTMH Baru di Talegong Garut. berita/55663/bendungan-pltmhbaru-di-talegong-garut.

[3] Wesli, Ir, 2008, Drainase Perkotaan. Graha Ilmu, Yogyakarta.

[4] Satria, Agung. 8 Juni 2012. Presentasi Pembangkit Listrik Tenaga Mikrohidro (PLTMH)

[5] Dwiyanto very, dan kawan kawan, 2016. Analisa Pembangkit Listrik Tenaga Mikrhidro(PLTMH) studi kasus: sungai air anak (Hulu sungai way besai) JRSDD,edisi September 2016 Vol.3, No.4, Hal:407(ISSN :2303:011) 
[6] Andika hanna,7 oktober 2016. Generator Sinkron Arus DC Di Terapkan Pada Lilitan Untuk Menghasilkan Medan Magnet Rotor. malang

[7] Fauziah,sri. 2017. Perancangan Pembangkit Listrik Tenaga Mikrohidro. TA.Prodi elektronika departemen teknik elektro fakultas vokas ITS.surabaya

[8] Aris Munandar, Artha,1982, Pembangkit Listrik Tenaga Air, Praditya Paramita, Bandung

[9] Dietzel, F., Sriyono, Dakso, 1993, Turbin Pompa dan Kompresor, Erlangga, Jakarta.

[10] Prasetyo, A. D. N. B., Priyo, H. A., 2016, Uji Eksperimental Pengaruh Variasi Banyak Sekat Pada Sudu Terhadap Daya dan Efisiensi Turbin Reaksi Cossflow Poros Vertikal Dengan Sudu Setengah Silinder, JTM, Universitas Negeri Surabaya, Volume 04 Nomor 03, 461-468.

[11] Viktor, L , streeter E dan benyamin wylie, 1993. Mekanika Fuida Jilid I Edisi Delapan. Erlangga .jakarta

[12] Wibowo, w . 2002. Kincir Air Pembangkit Listrik, Universitas Senata Dharma, Jogjakarta

[13] Jufri, S. Umar. 2018. Analisis Awal Potensi Renewable Energy di Bawah Jembatan Aur Duri II Jambi, Journal of Electrical Power Control and Automation Vol.1 No.1 Juni 2018 e-ISSN 2621$556 \mathrm{X}$ 